\author{
I.I. Shtablavyi, S.I. Mudry, U.I. Liudkevych
}

\title{
The Transformation of the Structure at Heating and Mechanism of Thermal Expansion of Sn-Bi Eutectic Alloy
}

\author{
Ivan Franko National University of Lviv, Kyrylo and Mephodii str., 8, 79005 Lviv, \\ Ukraine, ihor.shtablavyi@lnu.edu.ua
}

\begin{abstract}
The short range order structures of $\mathrm{Sn}-\mathrm{Bi}$ eutectic melt has been studied by means of $\mathrm{X}$-ray diffraction and reverse Monte-Carlo methods within $420-1120 \mathrm{~K}$ temperature range. Temperature dependences of interatomic distances and thermal expansion coefficient within first coordination sphere were calculated. Free volume temperature variation was investigated using Voronoi-Delone statistic-geometric method. Obtained data allowed us to find the occurrence of smeared structure transformation in $\mathrm{Sn}-\mathrm{Bi}$ liquid eutectic and determine the temperature range of this transformation. Results of this study have a potential application in soldering technologies, particularly at improving of interface region properties.
\end{abstract}

Kew words: short range order structure, thermal expansion, free volume.

Article acted received 02.03.2017; accepted for publication 05.06.2017.

\section{Introduction}

Rapid advancement of micro- and nanoelectronics compels the deeper studying of the soldering processes and their improving in order to construct more effectively the multifunctional electronic systems by connecting of few units. Generally it is clear that high perfection and productive capacity of electronic units cannot be successfully employed without reliable and long-term connecting. The soldering process is one of the most optimal ways to connect the units of various nature (metals, polymers etc.) and is most widely used for connecting of units with metallic or semiconducting properties, which is related with using of various solder alloys, composed of different elements with some definite content [1]. Solders on the base of $\mathrm{Sn}-\mathrm{Pb}$ eutectic alloy posses good properties, needed for soldering and they during long time were widely used but now in Europian Community and other countries these alloys are prohibited due to toxicity of lead. On that reason the intensive experimental studies aimed to searching the lead-free solderswith properties similar to ones of $\mathrm{Sn}-\mathrm{Pb}$ solders are carried out at present time [24]. There are few most important physical characteristics, by which must possess the solders: good solder acceptance to connecting surfaces; low melting temperature $(\sim 450 \mathrm{~K})$; good mechanical properties; counteraction against tin whisker crystals growth; rapid formation of thin layer of intermetallic phase at connecting boundary etc. [5-7]. The last two factors really are most important at formation first of all the mechanical properties of connection. The formation of solid phases notably depends also on composition of solder alloy as well as temperature conditions at soldering process. Therefore growth of interest to studies of physical-chemical properties of alloys, which are promising for soldering is based on the attempts to search the most suitable alloy compositions and soldering conditions in order to optimize the soldering processes.

Among a lot of binary systems, which can be considered as candidate materials for soldering $\mathrm{Sn}-\mathrm{Bi}$ binary is attractive due to most important characteristics of their constituent elements- $\mathrm{Sn}$ and $\mathrm{Bi}$ and phase diagram features. Namely the alloy containing 43 at. $\%$ of $\mathrm{Bi}$ is an eutectic alloy with melting temperature of $412 \mathrm{~K}$. One of the advances of this system is that there are no any chemical compounds, which commonly impair the mechanical properties. Besides, these alloys are cheaper comparatively with another of low melting temperature systems and data on their properties are sufficiently published [8].

As follows from results of experimental studies on interaction of solders on the base of $\mathrm{Sn}-\mathrm{Bi}$ system with copper substrate at first the formation of $\mathrm{Cu}_{6} \mathrm{Sn}_{5}$ compound with further creation of $\mathrm{Cu}_{3} \mathrm{Sn}$, commonly formed at aging process, occurs [9], whereas no the formation of any compounds of $\mathrm{Bi}$ with $\mathrm{Cu}$ [10]. At formation of soldering connections on substrate of $\mathrm{Ni}$ the formation of $\mathrm{Ni}_{3} \mathrm{Sn}_{4}$ compound is the main result on 
interaction between liquid $\mathrm{Sn}-\mathrm{Bi}$ eutectic and solid $\mathrm{Ni}$. Another compound $\mathrm{NiBi}_{3}$ forms only when the cointent of Bi-atoms attains $98 \%$ [11]. It is shown also that both doping of solder with some elements and temperaturetemporal conditions significantly effect the formation of intermetallic layer at the boundary of connection. It should be noted that numerous studies on influence of temperature and duration on soldering process can not clearly and completely explain the kinetics of intermetallic phases formation and consequently to obtain the recommendations for soldering technology[1215]. In order to avoid such disadvantages detailed study of physical-chemical factors, which can effect the diffusive processes and phase formation process at solder - substrate boundary. One of the such factors is atomic structure of liquid solder and its variation with temperature, because the structure changes are related with change of most important for soldering properties.

The structure of majority of liquid metals and their alloys, including Sn-Bi binary melts, is studied in detail by means of diffraction methods [16] as well as by measurements of structure-sensitive physical properties. Structure parameters, obtained from diffraction studies and physical properties measurements for Sn-Bi binary system are available within wide concentration range and at different temperatures [17-20].Analysis of main publications allowed to note the existence of preferred interaction between unlike kind atoms that leads to formation of dimmers [17] and clusters, which are stable within wide temperature range. Particularly the data on structure, obtained within concentration range 25-60 at. $\% \mathrm{Bi}$, allowed to conclude the existence of few kinds of clusters $\left(\mathrm{Sn}_{75} \mathrm{Bi}_{25}, \mathrm{Sn}_{64} \mathrm{Bi}_{36}, \mathrm{Sn}_{53} \mathrm{Bi}_{47}\right.$ and $\left.\mathrm{Sn}_{40} \mathrm{Bi}_{60}\right)$, which are stable at temperatures close to melting points [18]. According to data of [19] the temperature increasing leads to rearrangement of atoms in clusters $\mathrm{Sn}_{53} \mathrm{Bi}_{47}$, whose concentration corresponds the eutectic alloy. Notably that such rearrangement is not accompanied with significant change of main structure parameters such as most probable interatomic distance and number of neighbors. Experimental data on electrical resistivity [20] and their temperature dependences indicate the possibility of notable structure transformation by means of collective migration of atoms in $700-800 \mathrm{~K}$ temperature range.

As follows from above mentioned the melting process and further heating of $\mathrm{Sn}-\mathrm{Bi}$ melts is accompanied with structure transformation, occurrence of which has a significant influence on wetting, diffusion, phase formation and crystallization of alloys. Taking into account such features, in this work we attempt to carry out the detailed studies of structure of liquid eutectic alloy $\mathrm{Sn}_{57} \mathrm{Bi}_{43}$ within temperature range $420-1120 \mathrm{~K}$.

\section{Experimental}

The structure of the melts was studied using a hightemperature X-ray diffractometer, which allowed the intensity curves of the diffracted radiation to be obtained at various temperatures up to $1400 \mathrm{~K}$. The sample was placed in a helium-filled chamber of a diffractometer to prevent its oxidation. The geometry of an incident X-ray beam, monochromated using a LiF crystal, a center of the camera, and an inlet slit of the detector, corresponded to the Bragg-Brentano type focusing geometry [21]. The accuracy of the measurement of the X-ray intensity was in the range of $2-3 \%$ and depended on the selected exposure time at each point. The temperature was measured and maintained with an accuracy of $\pm 2 \mathrm{~K}$.

The experimental dependences of the intensity were smoothed by the least squares method, and after that, were corrected on polarization, absorption and anomalous dispersion. Normalization to electron units was carried out using the method described in [22]. Corrected and normalized X-ray diffraction curves were used to calculate structure factors $(\mathrm{SF})$, pair correlation functions (PCF), and radial distribution functions of atoms. These functions allowed us to calculate the main short range order parameters $r_{1}$ - the most probable interatomic distances, and $\mathrm{Z}$ - the number of nearest neighbors. In addition to the analysis of the most probable interatomic distances, the temperature dependences of the mean and root mean square interatomic distances were also analyzed, as well as the temperature variations of the edge of the first coordinating sphere which were determined as the position of the minimum at the first maximum of the PCF. The profile of the structural factor was also analyzed, the position of its main maximum $\mathrm{k}_{1}$ and its height $\mathrm{S}\left(\mathrm{k}_{1}\right)$ has been determined.

The most probable interatomic distances were determined by the position of the first maximum of the pair correlation function, and the mean and root mean square interatomic distances were calculated according to the equations:

$$
<r_{1}>=\frac{\int_{r_{0}}^{r_{\min }} r g(r) d r}{\int_{r_{0}}^{r_{\min }} g(r) d r} \quad \sqrt{<r_{1}^{2}>}=\sqrt{\frac{\int_{r_{0}}^{r} r^{2} g(r) d r}{r_{r_{0}}^{r i n} g(r) d r}}
$$

Using the temperature dependence of the density, as well as the temperature dependences of the most probable, mean and root mean square interatomic distances, the coefficient of thermal expansion was calculated.

$$
\begin{gathered}
\beta_{\rho}=-\frac{1}{\rho} \frac{d \rho}{d T} \\
\beta_{m p}=\frac{3}{r_{1}} \frac{d r_{1}}{d T} \\
\beta_{m d}=\frac{3}{<r_{1}>} \frac{d<r_{1}>}{d T} \\
\beta_{r m s}=\frac{3}{\left(<\mathrm{r}^{2}{ }_{1}>\right)^{1 / 2}} \frac{d\left(<\mathrm{r}_{1}^{2}>\right)^{1 / 2}}{d T}
\end{gathered}
$$

For a more detailed study, the reconstruction of the structure of the molten $\mathrm{Sn}_{57} \mathrm{Bi}_{43}$ eutectic alloy was carried out by the reverse Monte Carlo method (RMC). For the 
simulation process, the cubic cell that contained 10,000 atoms was created. The dimensions of the model cell were selected according to the melt density at the experimental temperature. The minimum distances between atoms $r_{i j}$ was took as the point of intersection of the left branch of the first maximum in an experimental PCF curve with the abscissa axis. As a result, the partial pair correlation functions have been obtained which were used to determine the partial interatomic distances and the edges of the first coordination sphere. The distribution of atoms in the simulated cell was used to calculate the free volume according to the generally accepted method [23].

\section{Results and discussion}

As it is known the main conclusions about the structure of liquids can be derived from analysis of SF and calculated from them PCF. Analysis of SF, obtained at different temperatures (Fig. 1) indicates the anomalous profile of their principal peaks, especially at temperatures not far from melting point. One can see the presence of shoulder on right hand side of principal peak, which is pronounced due to existence of atomic groups in which mean distance between atoms is less than most probable interatomic distance.

As was noted in [17], in Bi- and Sn-based alloys, dimers can be present on the basis of atoms of the same kind, or on the base of pairs of different kind of atoms. The structure of such alloys can not be described within the framework of a simple hard sphere model, but it is possible to do this by introducing an additional repulsion parameter at distances $\sigma<\mathrm{r}<\lambda \sigma$. According to this model, the change in the height of the first maximum of the SF is caused by similar changes in the average atomic density $\rho_{0}$.

As can be seen from Fig. 2, the height of the SF first

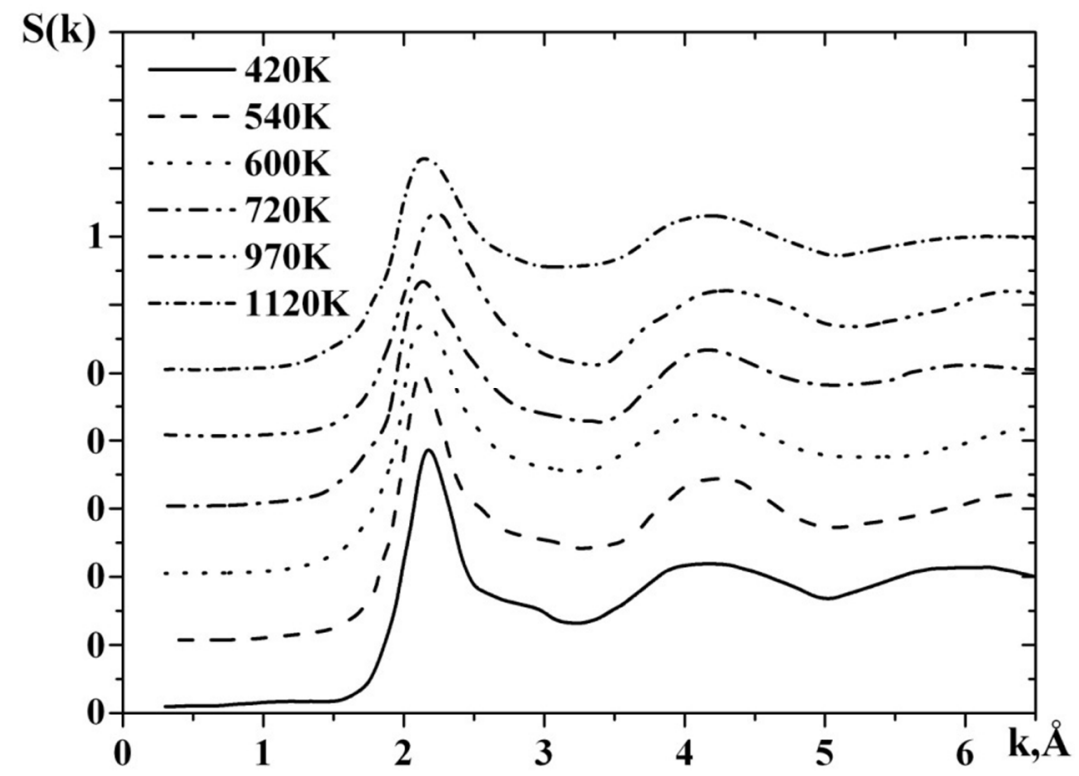

Fig. 1. SFs for $\mathrm{Sn}_{57} \mathrm{Bi}_{43}$ eutectic melt at different temperatures.

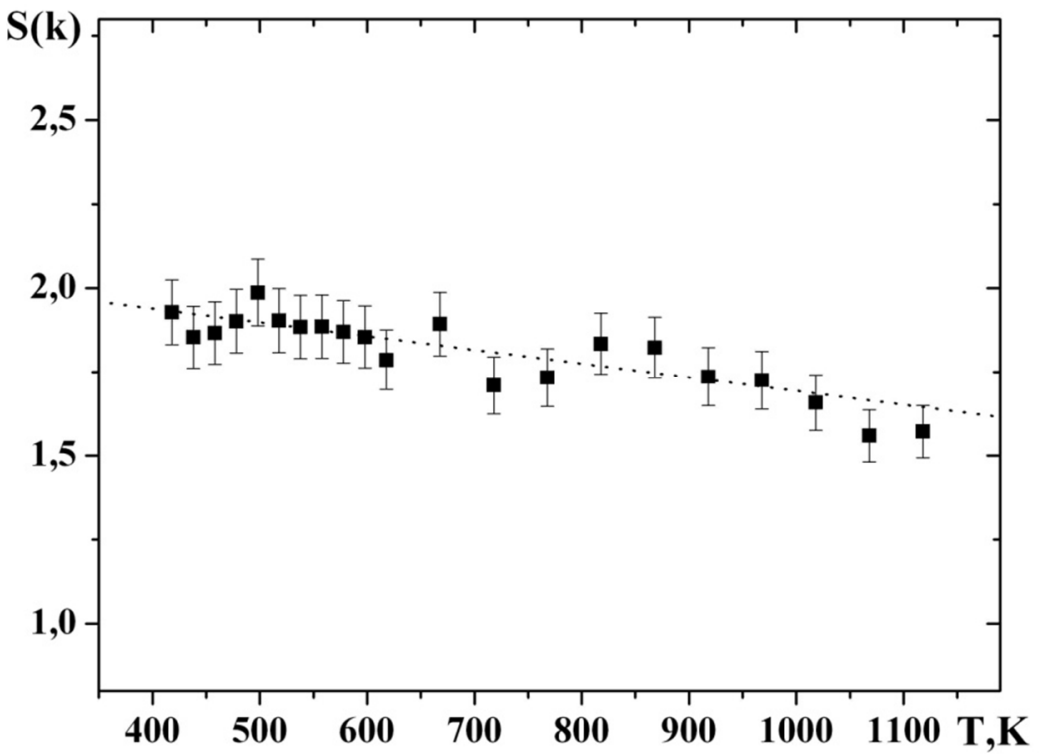

Fig. 2. Temperature dependence of the SF first maximum height for a $\mathrm{Sn}_{57} \mathrm{Bi}_{43}$ liquid eutectic alloy. 
maximum linearly decreases with increasing the temperature. Such behavior of this parameter is typical for most of the melts and indicates a decrease in the average number of atoms per unit volume of the melt. In view of the significant interaction between the atoms forming the dimmers, the decrease of the average atomic density at temperatures close to the melting point can not be caused by an increase in interatomic distances.

As we can see in Figure 3 , the increase in the temperature within the frame of $420-950 \mathrm{~K}$ leads even to a slight decrease in distances, and only at temperatures above $950 \mathrm{~K}$, we observe an increase of them. This behavior concerns not only to the most probable interatomic distances, but also to mean and root mean square interatomic distances, which take into account the asymmetry of distribution of interatomic distances within the first coordinating sphere in relation to the position of the first maximum of the PCF.
The decrease in interatomic distances is accompanied by a decrease in the coordination number (Fig. 4), which leads to the consolidation of the short range order structure within the first coordination sphere.

More detailed information on the transformation of the short-range order structure can be obtained from the analysis of partial structural parameters, in particular, the partial most probable interatomic distances $r_{i j}$ (Fig. 5) and partial distances, which characterize the edge of the first coordination sphere $r_{i j}^{\min }$ (Fig. 6). As we can see, the temperature increase from $420 \mathrm{~K}$ to $800-900 \mathrm{~K}$ leads to a decreasing of the partial interatomic distances and the edge of the first coordination sphere, which indicates the compaction of the structure within the first coordination sphere. Further increase in temperature leads to an increase in these parameters, thereby

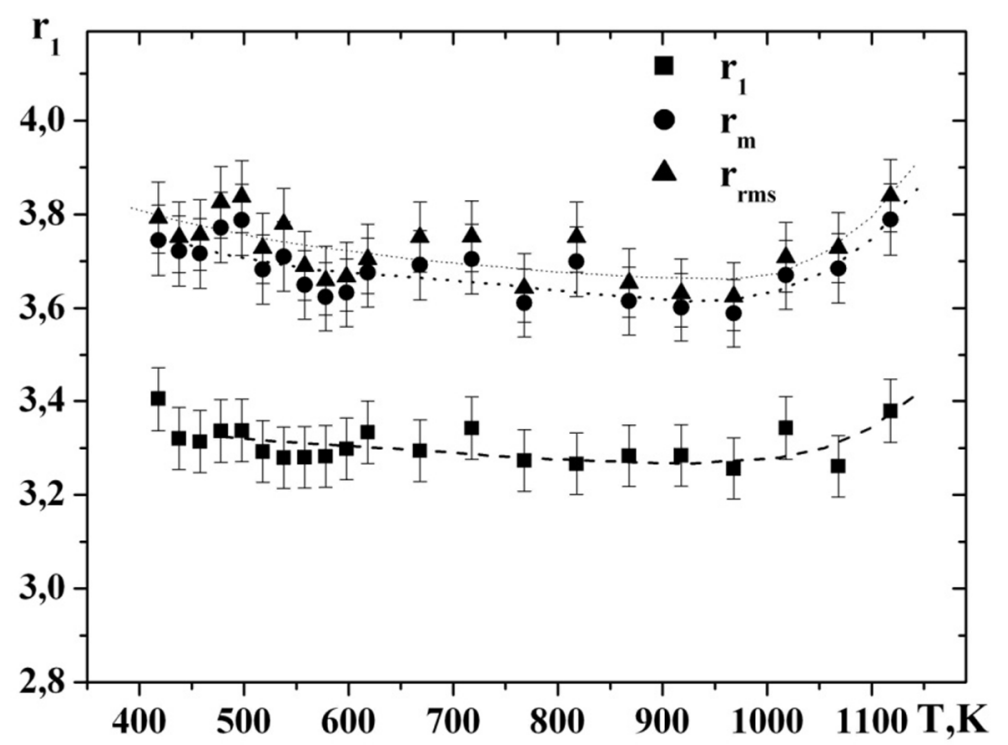

Fig. 3. Temperature dependence of the interatomic distances for a $\mathrm{Sn}_{57} \mathrm{Bi}_{43}$ liquid eutectic alloy.

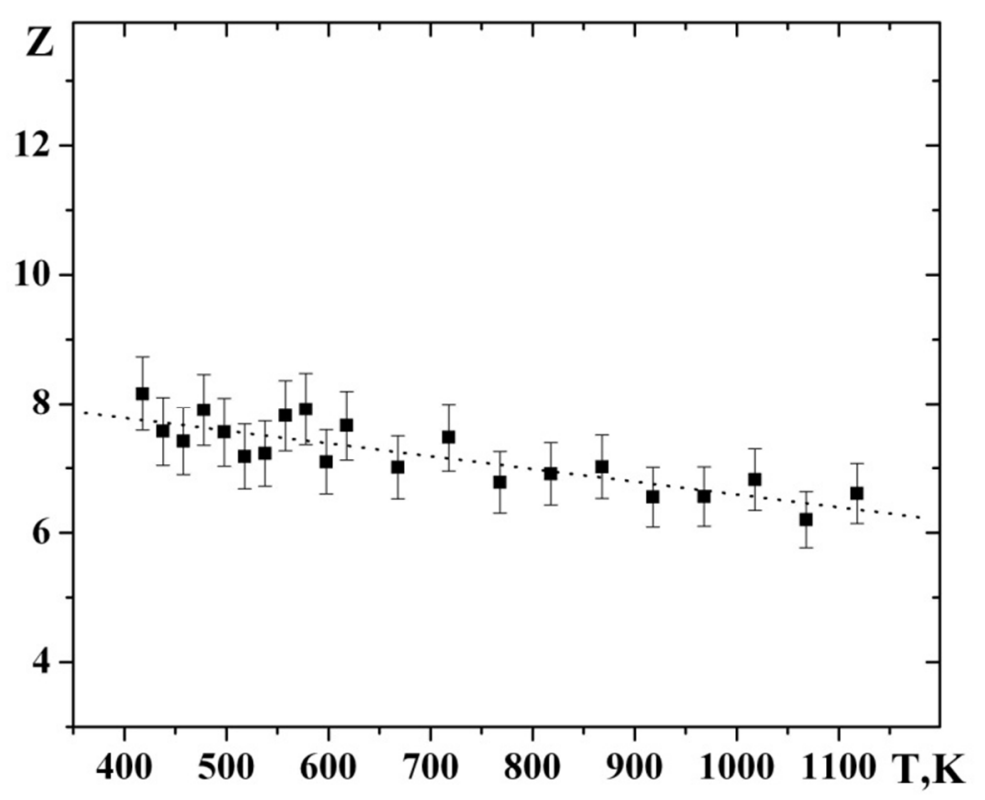

Fig. 4. Dependence of coordination number on temperature for $\mathrm{Sn}_{57} \mathrm{Bi}_{43}$ liquid alloy. 
indicating significant structural transformations in a liquid state. The temperature range of $800-900 \mathrm{~K}$, in which the changes in the temperature dependences of the main structural parameters occur, coincide with the temperatures of the anomalous changes in the electrical conductivity and the viscosity of the $\mathrm{Sn}_{57} \mathrm{Bi}_{43}$ liquid eutectic alloy [20, 24]. Such anomalous changes of the indicated structural sensitive properties may appear as a result of structural transformations, which are accompanied by a decrease in the size of the clusters in the liquid and the transition from the microinhomogeneous structure to the atomic solution.

The temperature dependences of the interatomic distances allowed us to calculate additionally the coefficient of thermal expansion of the investigated eutectic alloy within the first coordinating sphere (local coefficient) according to the equations (2) - (4) and compare it with the coefficient of thermal expansion calculated from the temperature dependence of the density (Fig. 7). As can be seen, in the temperature range of $420-950 \mathrm{~K}$, the local coefficient of thermal expansion is negative, while the coefficient of thermal

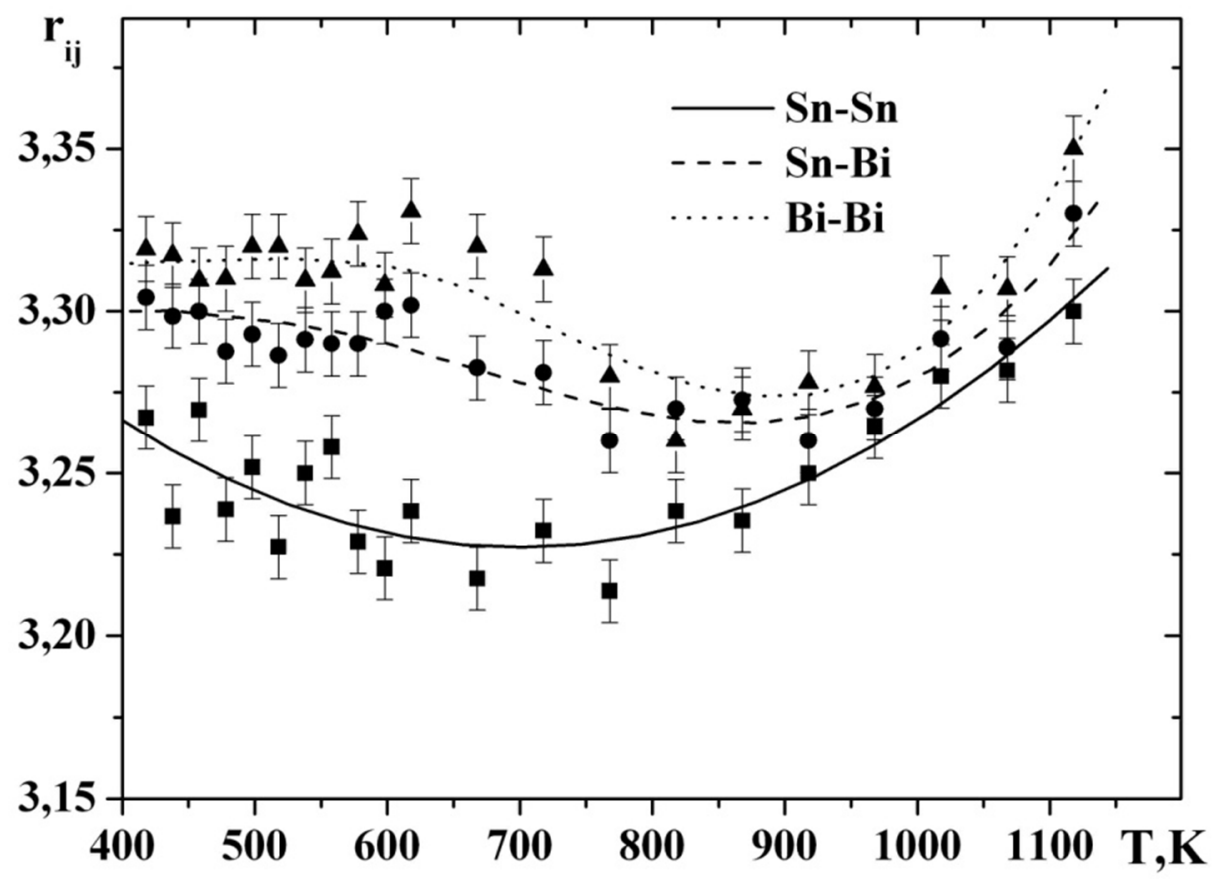

Fig. 5. Temperature dependencies of partial most probable interatomic distances fir $\mathrm{Sn}_{57} \mathrm{Bi}_{43}$ melt.

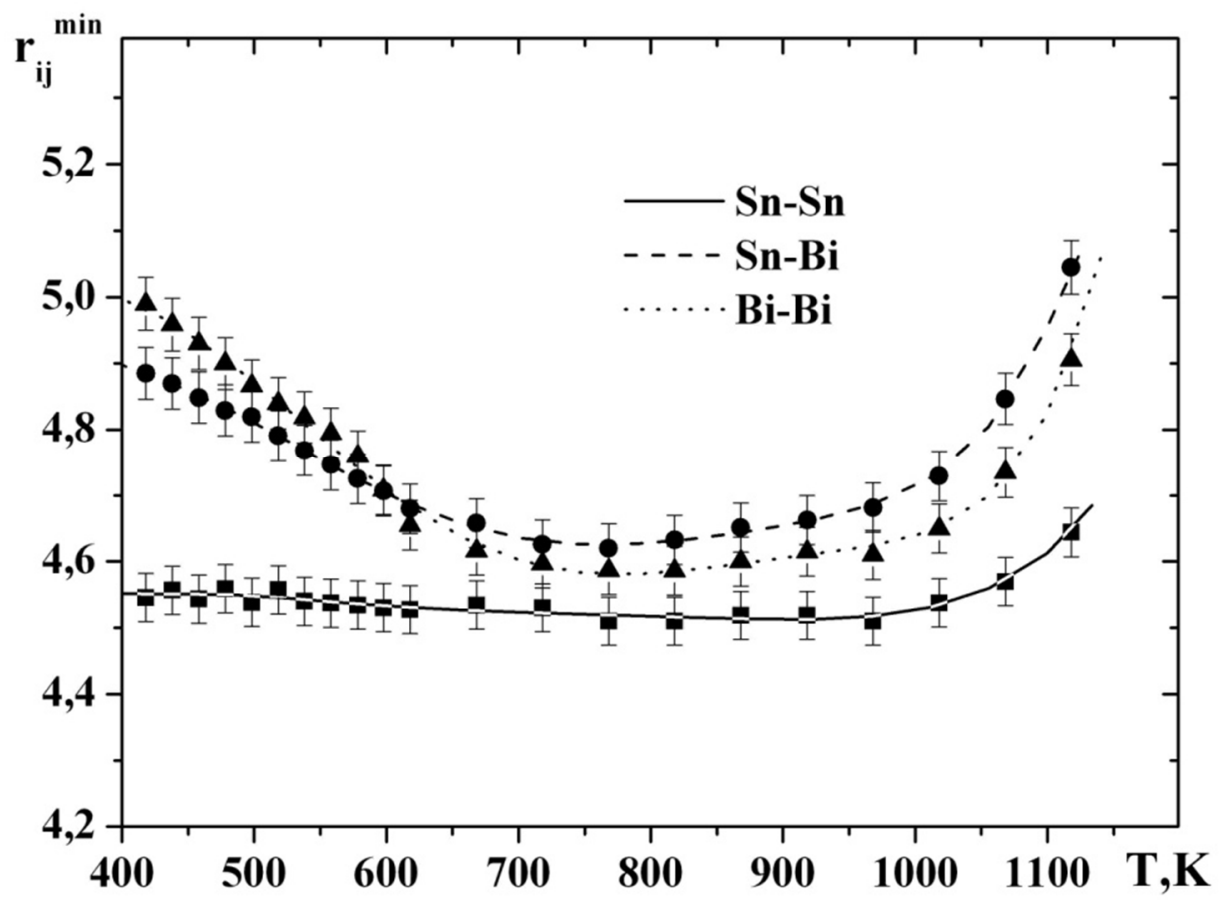

Fig. 6. The dependence of the edge of the first coordinating sphere of the $\mathrm{Sn}_{57} \mathrm{Bi}_{43}$ liquid eutectic alloy on the temperature. 
expansion calculated according to the temperature dependence of the density is positive in the whole temperature range. Such a feature of the temperature dependence of the coefficient of thermal expansion indicates the compaction of the local liquid structure within the first coordination sphere, and at the same time the increasing in the volume of the liquid as a result of thermal expansion. Such changes are possible only in the case of the transformation of free volume in the melt.

Using the distribution of atoms in a cell for modeling the structure by the Reverse Monte Carlo method, a free volume was calculated according to the method described in [22] (Fig. 8). In this figure, the relative free volume $V_{f} / V$ (here $V$ - the volume of the model cell with atoms), and the relative fluctuation free volume $V_{f l} / V$ are given. As can be seen from the figure, the calculated relative free volume is too large due to the overlapping of the spheres inscribed in the cavity if the cavities have dimensions commensurable or larger than the size of the atom. To determine the degree of overlapping at different temperatures, the ratio of free volume calculated from the density data $V_{0}$ to the free volume $V_{f}$ was calculated. As we can see, the degree of

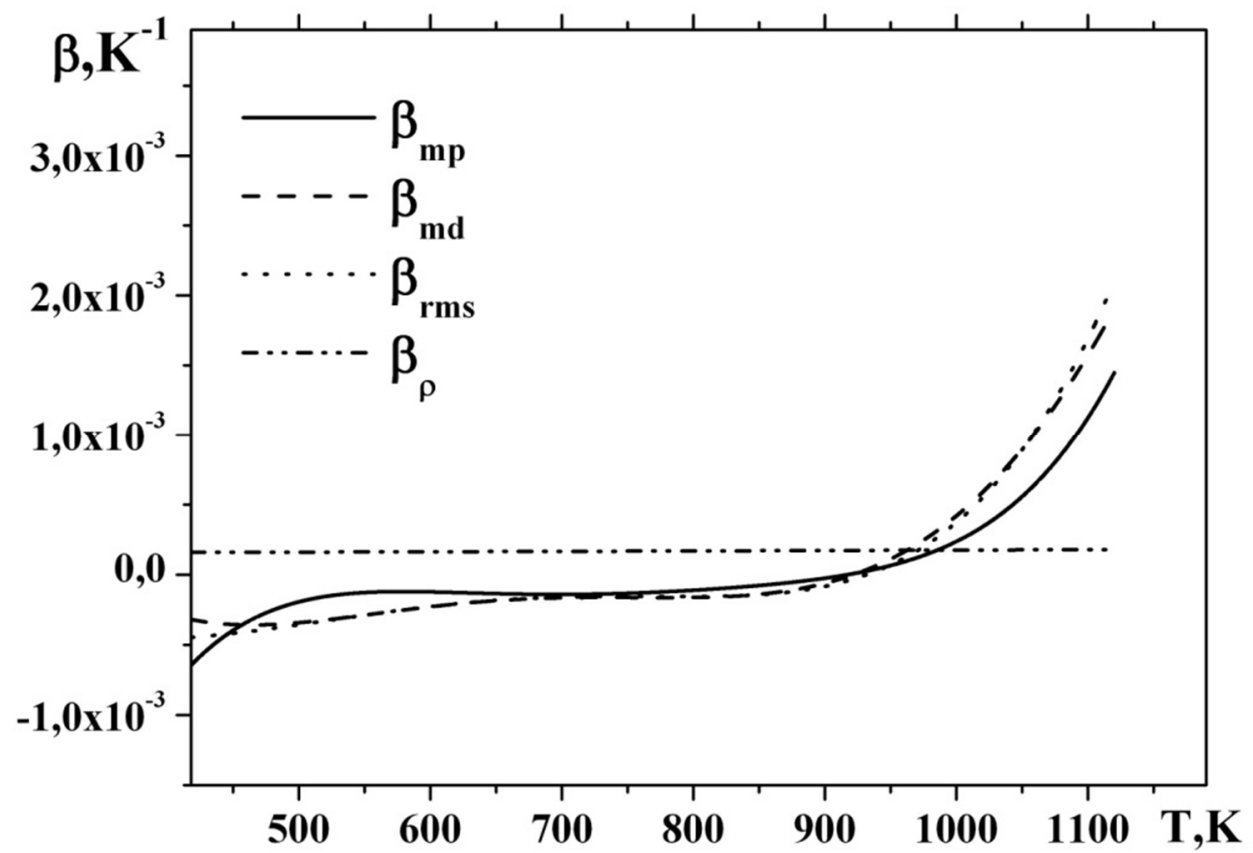

Fig. 7. Temperature dependence of the thermal expansion coefficient for $\mathrm{Sn}_{57} \mathrm{Bi}_{43}$ eutectic alloy.

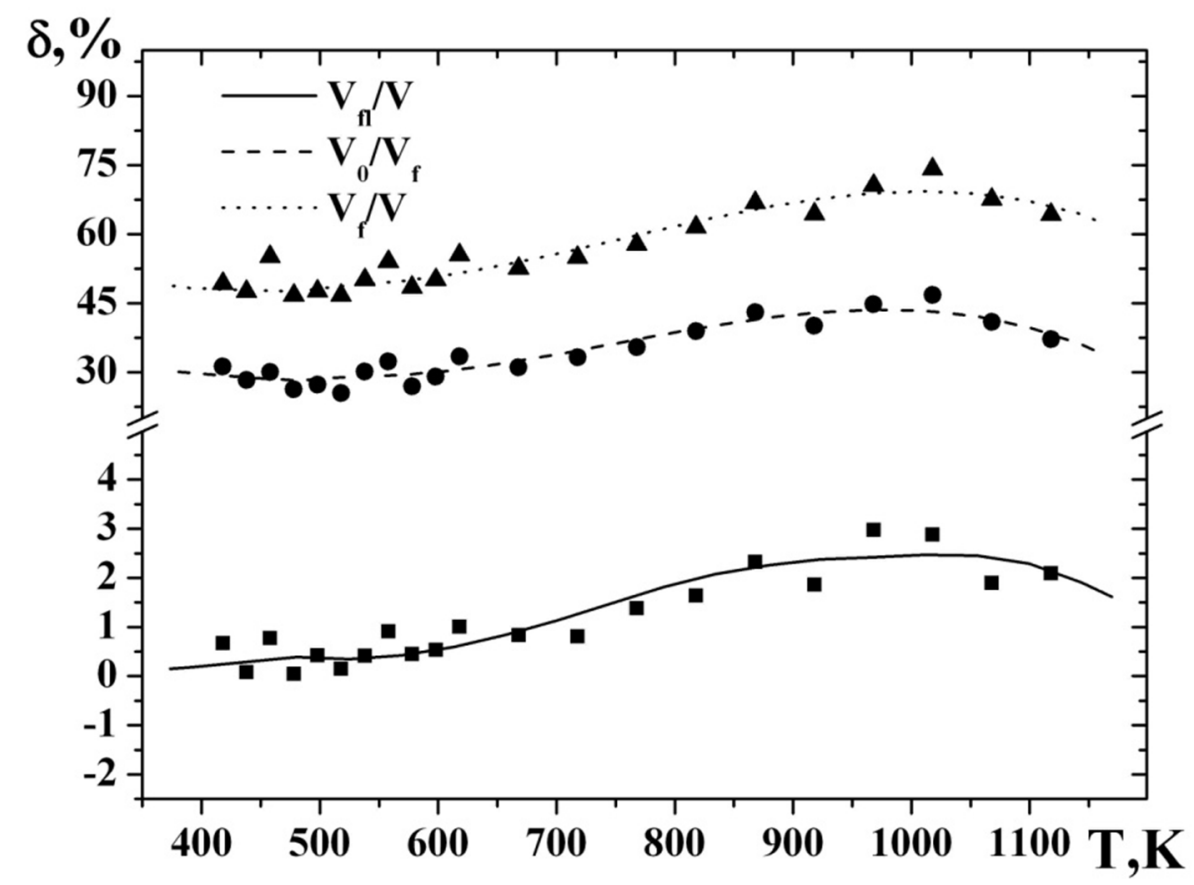

Fig. 8. Dependence of free volume on the temperature of $\mathrm{Sn}_{57} \mathrm{Bi}_{43}$ liquid eutectics. 
overlapping is about $35 \%$. The dynamics of the change in the free volume with the temperature is consistent with the considerations mentioned above. In particular, in the range of $420-900 \mathrm{~K}$, an increase in free volume is observed, and with further heating, it even decreases somewhat.

\section{Conclusions}

As a result of the investigation of the structure of the $\mathrm{Sn}_{57} \mathrm{Bi}_{43}$ liquid eutectic alloy in a wide temperature range $(420-1120 \mathrm{~K})$, a nonmonotonic change in the values of interatomic distances in the within the first coordinating sphere was established. It was found that in the vicinity of temperatures of $800-900 \mathrm{~K}$ there is a change in the sign of the temperature dependence of both interatomic distances and the quantities associated with them - the volume coefficient of thermal expansion and free volume.

Negative values of the local coefficient of thermal expansion indicate the compaction of the short-range order structure in the frame of the first coordination sphere, resulting in an increase in the free volume. Upon reaching the temperature of $800 \mathrm{~K}$, structural transformations which associated with the transition from the microinhomogeneous structure of the melt to the statistical distribution of atoms are occur, resulting in increasing of interatomic distances within the first coordinating sphere, and the rate of increase in free volume decreases. The indicated temperature interval of structural transformations is consistent with the temperature interval of change in the viscosity and electrical conductivity of the $\mathrm{Sn}-\mathrm{Bi}$ alloys.

Shtablavyi I. - Candidate of Physical and Mathematical Sciences, Associate Professor of the Metal Physics Department;

Mudry S. - Doctor of Physical and Mathematical Sciences, Professor, Head of the Metal Physics Department;

Liudkevych $\boldsymbol{U}$. - Junior Researcher of the Metal Physics Department.

[1] M.E. Loomans, S. Vaynman, G. Ghosh, M.E. Fine, J Electron Mater. 23, 741 (1994).

[2] A. Rahn, The basics of soldering (NewYork: John Wiely \& Sons, 1993).

[3] K.N. Tu, Solderjointtechnology: material, properties, andreliability.(NY, USA: Springer 2007).

[4] H.R. Kotadia, P.D. Howes, S.H. Mannan, 54, 1253 (2014)

[5] T. Laurila, V. Vuorinen, JK. Kivilahti, Mater Sci Eng R - Rep.49, 1 (2005).

[6] T. Laurila, V. Vuorinen, M. Paulasto-Krockel, Mater Sci Eng R - Rep. 68, 1(2010).

[7] M. Abtew, G. Selvaduray,Mater Sci Eng R - Rep27, 95 (2000).

[8] F. Hua, Z. Mei, A. Lavagnino, Eutectic Sn-Bi asan alternative Pb-freesolder. In: Proceedings of aninternational summiton lead-freeelectronic sassemblies, IPC Works'99; S/03/08/01/06(1999).

[9] J. F. Li, S. H.Mannan, M. P. Clode, D. C. Whalley, D. A. Hutt, ActaMater 54, 2907 (2006).

[10] T. B. Massalski, Binary alloy phase diagram(Metals Park, OH: ASM., 1990).

[11] J. Li, S. H. Mannan, M. P. Clode, C. Liu, K. Chen, D. C. Whalley, Trans Compon Packag Technol. 31, 574 (2008).

[12] M. S.Suh, C. J. Park, H. S.Kwon, Materials Chemistry and Physics 110, 95 (2008).

[13] P.T. Vianco, A.C. Kilgo, and R. Grant, JournalofElectronicMaterials, 24 (10), (1995).

[14] H. Xiaowu,L. Yulong, Z. Min, MaterSci: MaterElectron, 24, 2027 (2013).

[15] W.H. Tao, Chem. Mater.13, 1051(2001).

[16] Y. Waseda, The structure of non crystalline materials(Mc. Graw-Hill, New York, USA, 1980).

[17] S. Takeda, S. Tamakiand Y. Waseda, Journal of the Physical Society of Japan 53(10), 3447 (1984).

[18] S. Mudry, I. Shtablavyi and I. Shevernoga, Physics and Chemistry of Liquids 50(5), 630 (2012).

[19] S. Mudry, I. Shtablavyi, I. Shevernoga,PolishJournalofChemical Technology, 15(3), 61 (2013).

[20] L. Mingyang, G. Haoran, L. Fang, Z. Min, L. Rongxue, L. Shujing, Journal of Molecular Liquids 204,27 (2015).

[21] V.K. Pecharsky, P.Y. Zavalij, Fundamentals of powder diffraction and structural characterization of materials (Springer, 2008).

[22] D.T. Cromer, J.T. Waber, Acta Crystallogr. 18(5), 104(1965).

[23] N.N. Medvedev, V.P. Voloshin, V.A. Luchnikov, M.L. Gavrilova, J. Comput Chem. 27, 1676 (2006).

[24] W. Aiqing, L. Guo, L. Changsong, J. Erguang, Z. Zhengang, Physica B 369, 51 (2005). 


\title{
I.I. Штаблавий, C.I. Мудрий, У.І. Людкевич
}

\section{Трансформація структури при нагріванні та механізм термічного розширення евтектики Sn-Bi}

\author{
Львівський наиіональний університет імені Івана Франка, вул. Кирила і Мефодія 8, 79005 Львів, \\ Україна, ihor.shtablavyi@lnu.edu.ua
}

\begin{abstract}
Методом високотемпературної рентгенівської дифрактометрії та оберненим методом Монте-Карло досліджено структуру ближнього порядку рідкої евтектики Sn-Bi в інтервалі температур 420 - 1120 K. Отримано температурні залежності міжатомних відстаней в межах першої координаційної сфери та об'ємного коефіцієнта термічного розширення. Використовуючи формалізм статистично-геометричного методу Вороного-Делоне досліджено зміну вільного об'єму зі зміною температури. Проведені дослідження дали змогу встановити наявність розмитого структурного перетворення рідкої евтектики і визначити температурну межу цього перетворення. Результати досліджень можуть бути використані для вдосконалення технології формування паяних з'єднань в електроніці та інших суміжних галузях.

Ключові слова: структура ближнього порядку, термічне розширення, вільний об’єм.
\end{abstract}

